\title{
Evidences of Thyroid Dysfunction in Case of Nodular Goiter (Ng)
}

\author{
Muhammad ameen* \\ Arid Agricultural University, Pakistan \\ *Corresponding author: Muhammad ameen, Pakistan
}

Submission: 海April 07, 2018; Published: 海 April 24, 2018

\begin{abstract}
The presence of solitary or multiple nodules including both hot and cold nodules in case of nodular thyroid disease is due to the risk of malignancy, toxicity, and local compressive symptoms. It is characterized by the number of separate lumps (nodules) in the enlarged thyroid gland at the age of puberty. Both hypothyroid and hyperthyroid patients are observed to have abnormal TSH concentrations. The comprehensive survey of 234 patients of nodular goiter carried out and evaluated statistically through chi (X2) Calculations in order to investigate various thyroid dysfunctioning based on the normal concentration of thyroid function tests. Hypothyroidism and hyperthyroidism can be accurately diagnosed with laboratory tests performed at Nuclear Medicine, Oncology and Radiotherapy Institute (NORI) Islamabad and other laboratories of Pakistan. The data along with detailed history was collected with the help of clinicians in NORI and entered in the Performa. TSH levels ranging from 0.27-4.2 $\mu \mathrm{IU} / \mathrm{ml}$ was considered as normal for the diagnosis in thyroid function tests (TFTs). Chi-square test was used to find the significance of study parameters on categorical scale between two or more groups. The diagnostic evaluation relating to functional and morphological characterization has examined through serum TSH concentration and imaging. Non-significant difference between hypothyroid and hyperthyroid patients of nodular goiter versus control group individuals was observed. The study has concluded that the prevalence of nodular goiter may be dependent on the higher and lower concentration of TSH. .
\end{abstract}

\section{Introduction}

Dixit et al. [1] have described that thyroid gland is a highly vascular endocrine gland that is placed anteriorly in the neck, extending from the fifth cervical to the first thoracic vertebrae. Evered et al. [2] have observed high serum TSH levels and normal T3 and T4 concentration in case of mild hypothyroidism while, Caldwell et al. [3] have examined low serum TSH levels and high levels of T3 and T4 concentration in case of hyperthyroidism due to negative feedback mechanism.

Yamada \& Mori (2008) have investigated that Hypothalamic pituitary-thyroid (HPT) axis have regulated the serum level of thyroid hormones production through the secretion of thyrotropin releasing hormone (TRH), which in turn stimulate the endocrine cells of pituitary gland when it is bounded to TRH receptors (TSH $\beta$-subunits). They have further examined that TSH secreted from pituitary gland stimulates the production of T3 and T4 in thyroid gland.

Khan et al. [4] have observed the two major disorders of thyroid gland, i.e. hyperthyroidism and hypothyroidism. They have further examined that in case of primary hypothyroidism serum TSH level has elevated but values of T3 and T4 have remained below the normal range.

Hermus [5] have examined that the prevalence of nodular goiter is significant in the population of Whickham, northeast England where palpable thyroid nodules were detected in 0.8 percent of adult men and 5.3 percent of adult women and their prevalence in Framingham, Massachusetts was determined to 1.5 percent of men and 6.4 percent of women between 30 and 59 years of age. In the latter population, new nodules appeared in 0.1 percent per year during a 15-year follow-up period. Thyroid nodules are even more commonly detected when the thyroid is examined by ultrasonography. The overwhelming majority of these nodules are benign.

Hollowell et al. [6] have reported that hyperthyroidism has involved in excess synthesis and secretion of thyroid gland that has led to leads to hyper metabolic indisposition as it has been observed in case of thyrotoxicosis. They have further described that it has triggered diffuse toxic goiter (Graves' disease), toxic multinodular goiter (Plummer disease) and toxic adenoma. Filteau have been observed that primary thyrotoxicosis has been involved the diffuse enlargement of the thyroid gland due to hyper-metabolism with ocular dysfunctions and excess secretion of T4 and T3 hormones. They have further described that secondary thyrotoxicosis is the result of excess TSH and T4 secretion due to nodular goiters (single or multiple).

Surks et al. [6] have described that a thyroid disorder is physical ailment that arises from its dysfunctioning that produces triiodothyronine (T3) and thyroxin (T4). They have further observed that this dysfunctioning have influenced functions of 
the pituitary gland and hypothalamus and consequently their secretions.

Oppenheimer et al. [7] have revealed that tetraiodothyronine (T4) is generated by the thyroid gland as an inactive compound. They have further described that this is transformed into the tissues to triiodothyronine (T3) that combines to the nuclear receptors in order to initiate thyroid hormone (TH) action. Guyton \& Hall [8] have analyzed that thyroid gland have produced about 7\% triiodothyronine (T3) and about 93\% thyroxin (T4). Triiodothyronine (T3) hasthe3-5 folds greater biological potency than fT4.

Pinchera [9] have revealed the fact that in areas where there is a lack of iodine (Italian regions) nodular Goiter has observed 25-33\% of the population, while in those areas where there is adequate iodine it has estimated between 0.4-7.2 percent. Biondi \& Cooper have examined that a hypo-echoic ultrasound examination have revealed the presence of thyroid peroxidase antibody (TPOAb) in autoimmune thyroid disease and TPOAb have not been discovered in $>20 \%$ of individuals having evidences of such disease.

Walsh (1999) have analyzed that the incidences of solitary nodules have estimated approximately $23 \%$ that are actually dominant nodules with multinodular Goiter. Mazzaferri (1992) has reported that roughly 5 to 10 percent of palpable nodules have developed thyroid carcinoma. He has further investigated that the degree of prevalence of nodular goiter depends upon the extent of iodine.

Pinchera [9] have observed that incidence of nodular goiter (25-33\%) in iodine deficient areas (Italian regions), and (0.4-7.2\%) in adequate iodine areas. Biondi \& Cooper 2008 have examined that a hypo-echoic ultrasound examination have revealed the presence of Thyroid peroxidase antibody (TPOAb) in autoimmune thyroid disease and TPOAb have not been discovered in $>20 \%$ of individuals having evidences of such disease.

Charib (1997) has been examined the incidence of solitary and multiple nodules in gender. He has been observed further that these are making proportion of $0.8 \%$ of men and $5.3 \%$ of women and their rate is increasing above 45 years in case of woman. It have been reported that reduced TSH levels in nontoxic goiter have shown different concentrations in circadian rhythms and slightly reduced TSH pulses have been observed (Brabant 1990) [10]. In case of sub-clinical hyperthyroidism (SH) sleep wake cycle of TSH pulses have been kept in unaltered condition down to $0.005 \mathrm{mU} / \mathrm{l}$, while variation in TSH pulses during day and night have been vanished at $0.002 \mathrm{mU} / \mathrm{l}$ (Roelfsema 2009).

Khandelwal \& Tandon (2012) have been examined that subclinical hypothyroidism is the initial stage during which thyroid-stimulating hormone (TSH) concentration rises while serum free thyroxin (FT4) and triiodothyronine (FT3) concentrations remains normal [11]. This kind of hypothyroidism has been transformed to overt hypothyroidism in approximately $2-5 \%$ cases annually. All patients having both disorders should get treatment when TSH $>10 \mathrm{mIU} / \mathrm{L}$.
The objective of study is to observe thyroid dysfunctions in patients of nodular goiter. Therefore, comparative evaluation of hormonal profile of subclinical and clinical hypothyroid and hyperthyroid patients with normal healthy individuals will be done statistically. Various medical disorders and abnormalities raised due to the abnormality of thyroid hormones will be explored in Pakistani population. Further, profile of thyroid hormones will be analyzed via level of different hormones and antibodies like TSH, FT4, T3 and ant thyroglobulin respectively will be analyzed from serum samples of patients. Analytical evaluation of the hormonal profile of patient will be carried out via electrochemiluminescent immunoassays (ECLIA) [12]. Such studies would be helpful to understand on the prevalence of nodular goiter (NG) in different subjects and will also suggest the measures to minimize the goiter associated with its onset.

\section{Materials and Methods}

The current study was carried out at Nuclear Medicine, Oncology and Radiotherapy Institute (NORI) between patients of nodular goiter (NG) and normal control group individuals. Population sample constituting 234 individuals was diagnosed through physical examination, thyroid scan, and ultrasound. The whole population was categorized into two major groups, one is experimental group and other is control group. The experimental group constituted 184 patients of nodular goiter (NG), while the control group constituted 50 individuals having not nodular goiter (NG) but they can have hypothyroidism or hyperthyroidism. Hypothyroidism and hyperthyroidism can be accurately diagnosed with laboratory tests performed at NORI and other laboratories of Pakistan. The normal and abnormal patients were designated through the normal range of thyroid functions tests (TFTs) ( 0.27 to $4.2 \mu \mathrm{IU} / \mathrm{ml}$ ). The clinical examination report of thyroid function tests were collected from various laboratories of Islamabad. In a whole sample of population, 131 patients were designated as normal and 53 patients as hyperthyroid or hypothyroid according to the values of TSH levels [13]. The study has worked out to determine the statistical difference between normal and hyperthyroid and hypothyroid versus control group individuals.

\section{Setting and study area}

The present study has been carried out in Nuclear Medicine, Oncology and Radiotherapy Institute (NORI).

\section{Study population}

Total 234 patients were included in the study.

\section{Inclusion Criteria}

All patients having nodular goiter in any age group will be included in the study.

\section{Exclusion criteria}

- $\quad$ Pregnancy

- $\quad$ Liver disease as evidenced by raised ALT level 
- Drugs: Amiodarone, lithium, anti-thyroid medications (neomercazole/procarbizole), thyroxin

Study Group: The study population was based on the prevalence of thyroid functions tests (TFTs) that were observed in the patients of nodular goiter (NG). Therefore, the whole population sample constituting the patients of nodular goiter (NG) has been based on types of goiter.

Data Collection: After having informed consent (Annexure-I) from patients, the data along with detailed history was collected with the help of clinicians in NORI and entered in the Performa (Annexure-II).

\section{Data analysis}

The data was analyzed using SPSS version 17. The average values for age, history of goiter (duration) etc. was calculated. The percentage of different thyroid dysfunctions (hypothyroid, hyperthyroid) in nodular goiter (NG) was calculated.

The study has considered Thyroid stimulating hormone (TSH) as a criterion for the diagnosis of thyroid dysfunction. The normal range of thyroid function (TFTs) regarding TSH diagnosed at NORI hospital is (0.27-4.2 $\mu \mathrm{IU} / \mathrm{ml})$ and other clinical laboratories of Pakistan. The patients having high TSH concentration have been designated as Hypothyroid and the patients having low serum TSH concentration have been designated as Hyperthyroid while the patients having normal TSH values are considered as euthyroid.

\section{Results}

The population sample of 234 individuals diagnosed through thyroid scan was evaluated through statistical analysis. The clinical diagnosis of the study patients of which 131 were diagnosed clinically as thyroid swellings but have normal concentration of TSH and 53 having abnormal TSH concentration as mentioned in Table 1 [14]. When the patients suffering from nodular goiter (NG) having the clinical symptoms of hypothyroid or hyperthyroid were compared with control group individuals, statistically nonsignificant difference was observed in this case, normal patients have shown statistically significant difference. Among 184 patients of nodular goiter, $29 \%$ have diagnosed abnormal, while $71 \%$ have normal TSH concentration. Among abnormal patients, about $87 \%$ have low, while $13 \%$ have high TSH levels. TSH levels ranging from $0.27-4.2 \mu \mathrm{IU} / \mathrm{ml}$ was considered as normal for the diagnosis in thyroid function tests (TFTs). The statistical evaluation of thyroid function tests in patients of nodular goiter has done in the statistical evaluation table.

\section{Discussions}

The statistical difference between hypothyroid and hyperthyroid patients of nodular goiter versus control individuals has demonstrated in Table 1. Comparison of lipid profile in euthyroid, subclinical, and clinical hypothyroid and hyperthyroid versus control group individuals showed non-significant differences by non-parametric tests ( $p>0.05$ ). Hypothyroid, Clinical and subclinical hypothyroid and hyperthyroid patients of nodular goiter have not altered lipid profile as compared to euthyroids that have demonstrated statistically significant difference. The study has observed that hormonal dysfunctioning was not equally prevalent in normal patients of experimental group and control group individuals. The prevalence of disease is dependent upon the concentration of TSH.

Table 1: $\mathrm{X}^{2}$ Calculations (Two-way Contingency) showing statistical difference between hypothyroid, hyperthyroid and normal TSH Patients of nodular goiter (NG) control individuals.

\begin{tabular}{|c|c|c|c|c|c|}
\hline $\begin{array}{l}\text { Patients with TSH } \\
\text { Concentration }\end{array}$ & Total No. & Male & Female & Control & P-Value \\
\hline \multirow{3}{*}{$\begin{array}{l}\text { Number of patients } \\
\text { with abnormal TSH } \\
\text { concentration }\end{array}$} & \multirow{3}{*}{53} & 11 & 42 & 50 & \multirow{3}{*}{0.3913} \\
\hline & & 12.86 & 40.14 & 50 & \\
\hline & & -0.27 & -0.09 & 0 & \\
\hline \multirow{3}{*}{$\begin{array}{l}\text { Number of patients } \\
\text { with high TSH } \\
\text { concentration }\end{array}$} & \multirow{3}{*}{46} & 9 & 37 & 50 & \multirow{3}{*}{0.3334} \\
\hline & & 11.02 & 34.98 & 50 & \\
\hline & & -0.37 & -0.12 & 0 & \\
\hline \multirow{3}{*}{$\begin{array}{l}\text { Number of patients } \\
\text { with low TSH } \\
\text { concentrations }\end{array}$} & \multirow{3}{*}{7} & 2 & 5 & 50 & \multirow{3}{*}{1.0926} \\
\hline & & 1.96 & 5.04 & 50 & \\
\hline & & 0 & 0 & 0 & \\
\hline \multirow{3}{*}{$\begin{array}{l}\text { Number of patients } \\
\text { with normal TSH } \\
\text { concentrations }\end{array}$} & \multirow{3}{*}{131} & 12 & 119 & 50 & \multirow{3}{*}{0.0012} \\
\hline & & 18.82 & 112.18 & 50 & \\
\hline & & -2.47 & -0.41 & 0 & \\
\hline
\end{tabular}


The result revealed that TSH, FT3 and FT4 levels affected the onset of goiter in both groups. While, both hyperthyroid and hypothyroid patients of nodular goiter have demonstrated statistically no significant difference that are contrary results to already published findings. However, hormonal imbalance was not more prominent in patients experiencing nodular goiter. Such studies would be helpful to understand on the prevalence of diffuse goiter in different subjects and will also suggest the measures to minimize the goiter associated with its onset. It is further suggested that that the role of hormonal interactions in these patients may also be investigated with reference to their different metabolic disorders.

\section{Conclusion}

Therefore, the research work has consistency with the findings of Dr. Firdushi Begum (2015) that estimation of serum thyroid hormones and a TSH concentration has great significance for the diagnosis of thyroid problem. The current study has supported the serum TSH concentration usefulness in determining thyroid problem, on this ground it is related to the findings of Dr. Firdushi Begum.

The research strategy is also not according to the findings of Ladenson et al. (2000) have also considered that the TSH test as a criterion for the diagnosis of thyroid dysfunction, especially in cases of minimal thyroid failure (subclinical hypothyroidism). Their studies shows that incidence of goiter is not dependent upon normal and abnormal TSH levels while current study has not supported it due to non significant results.

The study has inconsistency with the findings of Evered et al. [2] have been investigated that in case of mild hypothyroidism serum TSH also have been observed high and the values of T3 and $\mathrm{T} 4$ remains normal while this research strategy has negated that TSH concentration is more significant in determining thyroid dysfunction.

The present study concluded that prevalence of nodular goiter (NG) may be dependent on the extent of hormonal dysfunctioning specifically normal and abnormal TSH levels. In future comprehensive studies are warrant covering the epidemiological profile of the patients having nodular goiter (NG).

\section{References}

1. Dixit D, Shilpa MB, Harsh MP, Ravishankar MV (2009) Agenesis of isthmus of thyroid gland in adult human cadavers: a case series. Cases J 2: 6640 .

2. Evren B (2012) Introduction to thyroid: anatomy and functions. Thyroid and parathyroid diseases (4): 45-78.

3. Caldwell G, Gow SM, Sweating VM, Kellett HA, Beckett HJ, et al. (1985) A new strategy for thyroid function testing. Lancet 1(8438): 1117-1119.

4. Khan A, Muzaffar KMA, Akhtar S (2002) Thyroid disorders, etiology and prevalence. Med Sci 2(2): 89-94.

5. Hermus AR, Huysmans DA (1998) Treatment of benign nodular thyroid disease. Drug therapy N Engl J Med (338): 1438-1447.

6. Surks MI, Hollowell JG (2007) Age-specific distributionof serumthyrotropin and antithyroid antibodies in the US population: implications for the prevalence of subclinical hypothyroidism. J Clin Endocrinol Metab 92(12): 4575-4582.

7. Oppenheimer JH, Koerner D, Schwartz HL (1972) Specific nuclear triiodothyronine binding sites in rat liver and kidney. J Clin Endocrinol Metab 35(2): 330-333.

8. Guyton AC, Hall TE (1996) Text book of medical physiology ( $9^{\text {th }}$ edn), pp: 945-946.

9. Pacini F, Elisei R, Di Coscio GC, Anelli S, Macchia E, et al. (1988) Thyroid carcinoma in thyrotoxic patients treated by surgery. J Endocrinal Invest 11(2): 107-112.

10. Kumar V, Cotran RS, Robbins SL (1997) Basic pathdogy (6 $6^{\text {th }}$ edn), WB Saunders and co., pp. 643-652.

11. Morreale de Escobar G, Obregon MJ, Escobar Del Rey F (2004) Role of thyroid hormone during early brain development. Eur J Endocrinol 151(3): 25-37.

12. Schwartz CE, Stevenson RE (2007) The MCT8 thyroid hormone transporter and Allan Herndon Dudley syndrome. Best pract Res Clin Endocrinol Metab 21(2): 307-321.

13. Suzuki S, Nisiho S, Takeda T, Komatsu M (2012) Gender-specific regulation of response to thyroid hormone in aging. Thyroid Res 5(1): $34-45$.

14. Vander pump MPJ (2005) The epidemiology of thyroid diseases. In: BLE, Utiger RD (Eds.), Werner and Ingbarss the thyroid: a fundamental and clinical text $\left(9^{\text {th }}\right.$ edn). JB Lippincott-Raven, Philadelphia, USA, pp. 398496.
Creative Commons Attribution 4.0 International License

For possible submissions Click Here

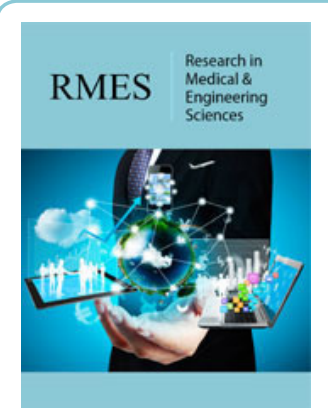

\section{Research in Medical \& Engineering Sciences}

\section{Benefits of Publishing with us}

- High-level peer review and editorial services

- Freely accessible online immediately upon publication

- Authors retain the copyright to their work

- Licensing it under a Creative Commons license

- Visibility through different online platforms 